\title{
NON-ENDEMIC GOITROUS CRETINISM
}

\author{
BY \\ A. D. M. JACKSON \\ From the Children's Department, The London Hospital
}

(RECEIVED FOR PUBLCATION JULY 9, 1954)

Enlargement of the thyroid gland is an unusual finding in cretins outside endemic goitrous areas. Wilkins, Clayton and Berthrong (1954), reviewing published cases of non-endemic goitrous cretinism, collected reports of 32 cases and described a further four cases of their own. Other cases have been reported by Rienhoff (1940) and Smallpeice (1949).

The hypothyroidism in these cases is of variable degree and the thyroid enlargement may appear at any time from infancy to adult life. Early administration of thyroid extract in adequate dosage causes the enlarged thyroid to return to normal size unless irreversible pathological changes have taken place in the gland. Subsequent withdrawal of the drug or reduction in dosage results in reappearance of the goitre. In glands which have been removed the histological changes are broadly those of hyperplasia leading to involution and fibrosis. Radioactive iodine studies have so far been reported in 26 cases (Hamilton, Soley, Reilly and Eichorn, 1943; Lerman, Jones and Calkins, 1946; Stanbury and Hedge, 1950; Stanbury, 1951; Hubble, 1953a; McGirr and Hutchison, 1953; Wilkins et al., 1954) and have shown that the enlarged thyroid glands have an unusual avidity for iodine, unlike cases of non-goitrous sporadic cretinism in which there is little or no uptake of radioactive iodine.

From these facts the aetiology of non-endemic goitrous cretinism would appear to be a complete or partial failure of production of thyroid hormone with, presumably, an excessive secretion of pituitary thyrotropic hormone resulting in hyperplasia of the thyroid gland. An identical condition may also be produced by the action of goitrogenic agents and is known to occur in the newborn infant following administration of thiouracil to the mother during pregnancy (Elphinstone, 1953). The high incidence of the disease in siblings suggests that the defect is genetically determined, possibly by a recessive mode of inheritance.

The rarity of this type of cretinism and the value of radioactive iodine studies in elucidating the exact nature of the defect of thyroid synthesis have stimulated this report of a further case.

\section{Case Report}

Elizabeth $\mathrm{C}$., an only child, was born at term weighing $7 \mathrm{lb} .13 \mathrm{oz}$. The mother's pregnancy had been normal but breast feeding was not established and the infant was fed on National dried milk. No abnormality was noticed by her parents until the onset of vomiting. stridor and difficulty in taking feeds at the age of 6 weeks. When first examined at 8 weeks the infant's appearance was suggestive of cretinism and there was enlargement of the thyroid gland; the blood cholesterol was $130 \mathrm{mg} . \%$. The vomiting ceased and no treatment was prescribed.

When admitted to The London Hospital at the age of 4 months the features of cretinism were definite but not gross (Fig. 1) and there was a diffuse enlargement of both

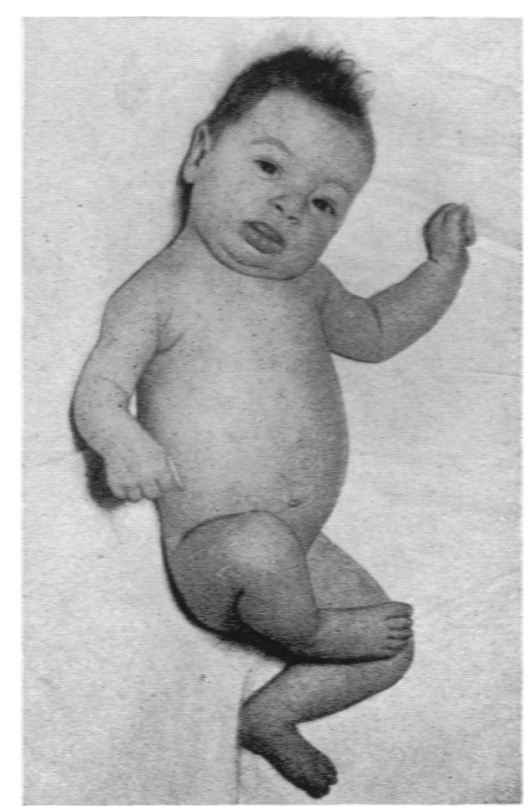

Fig. 1.-Elizabeth C., aged 4 months, showing the cretinous facies. 
lateral lobes of the thyroid gland, which was palpable but not visible. The tongue protruded from the mouth and there was some inspiratory stridor considered to be due to the large tongue. A small umbilical hernia was present. The infant was miserable, pale and inactive, and took only small feeds very slowly.

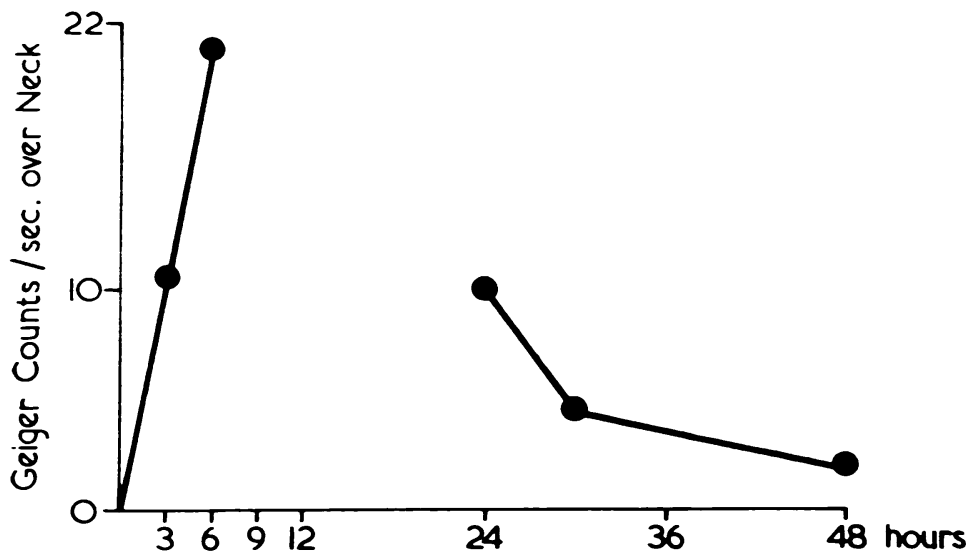

FKG. 2.-Radioactive iodine uptake following an oral dose of 2 microcuries. The initial uptake is high and rapid. Most of the $I^{131}$ has been released by 48 hours.

thyroid and recording the number of counts per second. Several readings were taken and the mean cakculated.

Results. Following a dose of 2 microcuries there was a rapid uptake of $I^{131}$ by the thyroid gland, a high level being reached within six hours (Fig. 2). The peak level was not determined but at 24 hours the level had fallen considerably and by 48 hours most of the accumulated I $^{131}$ had been released. These findings indicate that the patient's thyroid gland can take up iodine and does so with an avidity suggestive of a thyrotoxic gland. The rapid release of $I^{131}$ suggests a failure of conversion of iodide to an organic form in which it could be stored in the gland.

Further information was obtained by an experiment with potassium thiocyanate (KSCN) which blocks the uptake of $I^{131}$ and causes the immediate release from the thyroid gland of any iodine, normally only a very small quantity, not converted to an organic, protein-bound form (Vanderlaan and Vanderlaan, 1947).

Initial investigations showed anaemia (Hb 9.6 g. \%) and a raised blood cholesterol level (307 $\mathrm{mg} . \%$ ). The electrocardiogram was normal and the radiological bone age was not retarded. The results of radioactive iodine studies are discussed below.

As soon as the investigations were completed treatment was begun with dried thyroid, $\frac{1}{4}$ grain daily, the dose being increased gradually to grain daily. After six weeks of thyroid therapy there was complete remission of the cretinous features, the infant was happy and normally active, and the thyroid gland was no longer palpable.

The family history is of considerable interest. The parents are not related by blood and there is no history of thyroid disease in any other member of their families. The mother has been deaf since an attack of measles at the age of 7 years. She first noticed a swelling in the neck at the age of 15 , and a partial thyroidectomy was carried out when she was 22 years old. Histological section of the thyroid showed simple colloid goitre. The father is a deaf-mute and he, too, had a goitre, first noticed at the age of 8 , and removed by partial thyroidectomy at the age of 23 . The pathological appearances of his thyroid gland were those of nodular colloid goitre. Neither parent has ever had symptoms of hypo- or hyperthyroidism. There is no history of residence in an endemic goitrous area or exposure to any goitrogenic agent.

\section{Radioactive Iodine Studies}

Method. Carrier-free radioactive $\mathrm{I}^{131}$ was given by mouth. The thyroid uptake was assessed by placing a lead-screened Geiger-Müller counter over the enlarged
In order to magnify the effect the dose of $I^{131}$ was doubled in this test and the high uptake was again demonstrated (Fig. 3). Four hours after administration of $\mathrm{I}^{131}$ and two hours before the expected high level in the thyroid, 250 mg. KSCN was given by mouth. There was an immediate

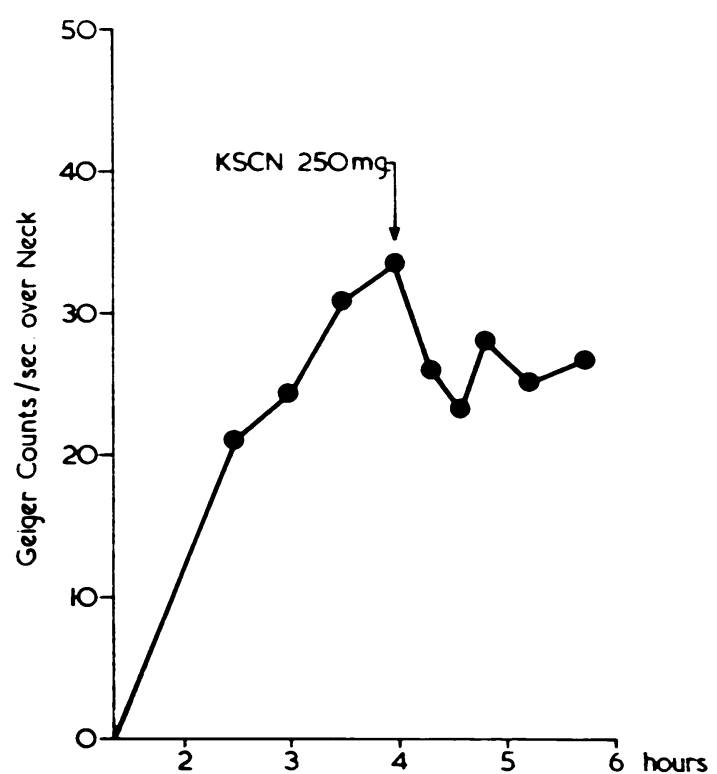

FKG. 3.-Radioactive iodine uptake following an oral dose of 4 microcuries. Administration of KSCN after four hours results in an immediate loss of approximately $30 \%$ of the accumulated dose. 
fall in the count over the neck of approximately $30 \% \mathrm{c}$. This result indicates that at least one-third of the radioactive iodine accumulated in the thyroid gland after four hours remained in an inorganic, unbound form.

The mother's radioactive iodine uptake was also investigated and was found to be normal.

\section{Discussion}

Results of radioactive iodine studies in previously reported cases have shown that the defect in nonendemic goitrous cretinism may occur at different stages in the elaboration or secretion of thyroid hormone. In almost all cases the ability of the thyroid gland to take up iodine to an unusual degree has been demonstrated, and it is in the subsequent behaviour of the gland that the differences arise. Hamilton et al. (1943) found thyroxine in the thyroids of two patients after removal and suggested that there was a failure to release the hormone from the gland. In one of the cases reported by Hubble (1953a) thyroxine was present both in the removed gland and, in small quantities, in the plasma. In this case it was considered that the failure of production was quantitative rather than qualitative. In a group of 12 cases McGirr and Hutchison (1953) obtained results which showed the defect to be in the final synthesis of the thyroid hormone from an organic iodine precursor. In only four previous cases has the response to KSCN shown the defect to be a failure of conversion of inorganic iodide to organic iodine compounds (Stanbury and Hedge, 1950: Stanbury, 1951). In these patients, whose ages ranged from 13 to 23 years, there was an immediate release of 70 to $90 \%$ of the accumulated dose of $I^{131}$ after administration of 1 or $2 \mathrm{~g}$. KSCN.

The results obtained with radioactive iodine suggest that the case reported here is probably of the latter type, the first to be reported in this country. The fact that only about $30 \%$ of the iodine uptake was expelled by $\mathrm{KSCN}$ may be explained either by the presumption of a partial rather than a complete failure of conversion or perhaps by the fact that the arbitrary dose of $250 \mathrm{mg}$. KSCN chosen for an infant of 4 months was too small to obtain a maximum effect. Further confirmation of the abnormality of the infant's thyroid would have been obtained from a study of the protein-bound iodine level in the plasma and by observing the effect of a larger dose of KSCN. This was not undertaken in the first instance in view of the risk to the patient of continuing to withhold thyroid therapy, but at a later date, when the infant's growth and development are established, it is intended to complete the investigations in full.

A perplexing aspect of this case is the significance of the colloid goitres in both the parents. The possibility of endemic goitre was considered in the father's case in view of the recognized association between this condition and deaf-mutism (Hubble, 1953b). However, in the absence of any family history of endemic goitre or of residence in an endemic area this diagnosis could not be upheld. Since neither parent has ever shown symptoms of hypothyroidism, and the mother has a normal radioactive iodine uptake, it is possible that the goitres in the parents are purely coincidental. It would, however, be more satisfactory, especially in view of the strong genetic factor in goitrous cretinism, to explain the occurrence of goitres in three members of a family on the basis of a similar defect. Such an explanation is, in fact, possible if it is assumed that the parents had suffered a minimal deficiency of thyroxine production which, in the periods of increased demand for hormone during childhood. had led to recurrent hyperplasia of the thyroid followed by involution, in a successful attempt to overcome the tendency to hypothyroidism. This train of events would explain the development of a colloid goitre. The subsequent maintenance of a euthyroid state, particularly after partial thyroidectomy, is difficult to explain although the demand for thyroid hormone might now be so small as to be met by even a diminished amount of imperfectly functioning thyroid tissue.

From a genetic point of view, in order to explain the incidence of what is probably a recessive defect in both parents of an affected individual, it is necessary to postulate an incompletely recessive gene which is responsible in the heterozygous parents for a mild form and in the homozygous infant for a severe form of the disease. This is undoubtedly labouring the theory and it must be concluded that the significance of the goitres in these parents is not at present completely understood.

\section{Summary}

A case of non-endemic goitrous cretinism is described.

The results of radioactive iodine studies indicate a failure of conversion of inorganic iodide to organic iodine compounds.

The significance of goitres in both parents is discussed and it is suggested that the abnormal gene in this family is an incomplete recessive.

The author wishes to acknowledge the advice and encouragement given by Dr. Richard Dobbs by whose permission the case is published. The radioactive iodine studies were devised and carried out by Dr. A. S. Mason of the Medical Unit, The London Hospital. whose experience and technical advice have been of great 
assistance. Suggestions concerning the genetics of the case were made by Dr. H. Harris.

\section{REFERENCES}

Elphinstone, N. (1953). Lancet, 1, 1281.

Hamilton, J. G., Soley, M. H., Reilly, W. A. and Eichorn, K. B. (1943). Amer. J. Dis. Child. 66, 495.

Hubble, D. (1953a). Lancet, 1, 1112 .

(1953b). In Garrod, Batten and Thursfield's Diseases of Chikdren, Sth ed., vol. I, p. 411, ed. A. Moncrieff and P. Evans. London.
Lerman, J., Jones, H. W. and Calkins, E. (1946). Ann. intern. Med., $25,677$.

MCGirr, E M and Hutchicon, J. H (1953), Lancet, 1, 1117.

Rienhoff, W. F., jr. (1940). Arch. Surg., Chicago, 41, 487.

Smallpeice $V$ (igs9) Lancet, 1,565 .

Stanbury, J. B. (1951). J. clin. Endocr., 11, 740

- and Hedge, A. N. (1950). Ibid., 10, 1471.

Vanderlaan, J. E. and Vanderlaan, W. P. (1947). Endocrinology, $40,403$.

Wilkins, L.. Clayton, G. W. and Berthrong, M. (1954). Pediatrics, 13, 235. 